\title{
Syringomyelia in the Tethered Spinal Cords
}

\author{
Ji Yeoun Lee, ${ }^{1,2}$ Kyung Hyun Kim, ${ }^{1}$ Kyu-Chang Wang ${ }^{1}$ \\ Division of Pediatric Neurosurgery,' Seoul National University Children's Hospital, Seoul, Korea \\ Department of Anatomy and Cell Biology, ${ }^{2}$ Seoul National University College of Medicine, Seoul, Korea
}

Cases of syringomyelia associated with spinal dysraphism are distinct from those associated with hindbrain herniation or arachnoiditis in terms of the suspected pathogenetic mechanism. The symptoms of terminal syringomyelia are difficult to differentiate from the symptoms caused by spinal dysraphism. Nonetheless, syringomyelia has important clinical implications, as it is an important sign of cord tethering. The postoperative assessment of syringomyelia should be performed with caution.

Key Words : Syringomyelia $\cdot$ Neural tube defects.

\section{DEFINITION}

Syringomyelia is a disorder in which a fluid-filled cystic cavitation (called a syrinx) forms inside the parenchyma of the spinal cord. Syringomyelia is commonly associated with Chiari malformation, spine trauma, and open neural tube defects. Only $12 \%$ of all patients with syringomyelia have occult spinal dysraphism. Of the various types of spinal dysraphism, $21 \%$ to $67 \%$ are reported to be associated with syringomyelia $^{7,13)}$. Myelomeningocele and split cord malformation are reported to be the most common disorders associated with syringomyelia, but the list seems to vary among studies.

"Terminal syringomyelia" refers to the condition where the syrinx resides in the distal third of the cord, and this condition is usually associated with cord tethering ${ }^{1)}$. However, syringomyelia in association with a tethered cord may extend far beyond the lumbar area, even up to the cervical region (Fig. 1).
The symptoms that may be caused by syringomyelia and cord tethering are difficult to distinguish, as there is significant overlap between the two : lower limb motor or sensory deficits, urinary symptoms, pain, foot deformities, and scoliosis. An exception is the symptoms involving the upper limbs in patients with spinal dysraphism, as these symptoms are almost always caused by syringomyelia.

\section{PATHOGENESIS}

Various theories on the pathogenesis of syringomyelia have been proposed, but the majority have focused on syringomyelia associated with hindbrain herniation. In terms of cases of an accompanying tethered cord, a recent group postulated that tensile radial stress on the spinal cord may cause syrinx, as the transient lower pressure of the cord parenchyma may

- Received : March 29, 2020 •Revised : April 3, 2020 •Accepted : April 6, 2020

- Address for reprints : Ji Yeoun Lee

Department of Anatomy and Cell Biology, Seoul National University College of Medicine; Division of Pediatric Neurosurgery, Seoul National University Children's Hospital, 101 Daehak-ro, Jongno-gu, Seoul 03080, Korea

Tel : +82-2-740-8205, Fax : +82-2-749-3485, E-mail : femiddang@naver.com, ORCID : https://orcid.org/0000-0003-0464-7605

This is an Open Access article distributed under the terms of the Creative Commons Attribution Non-Commercial License (http://creativecommons.org/licenses/by-nc/4.0) which permits unrestricted non-commercial use, distribution, and reproduction in any medium, provided the original work is properly cited. 


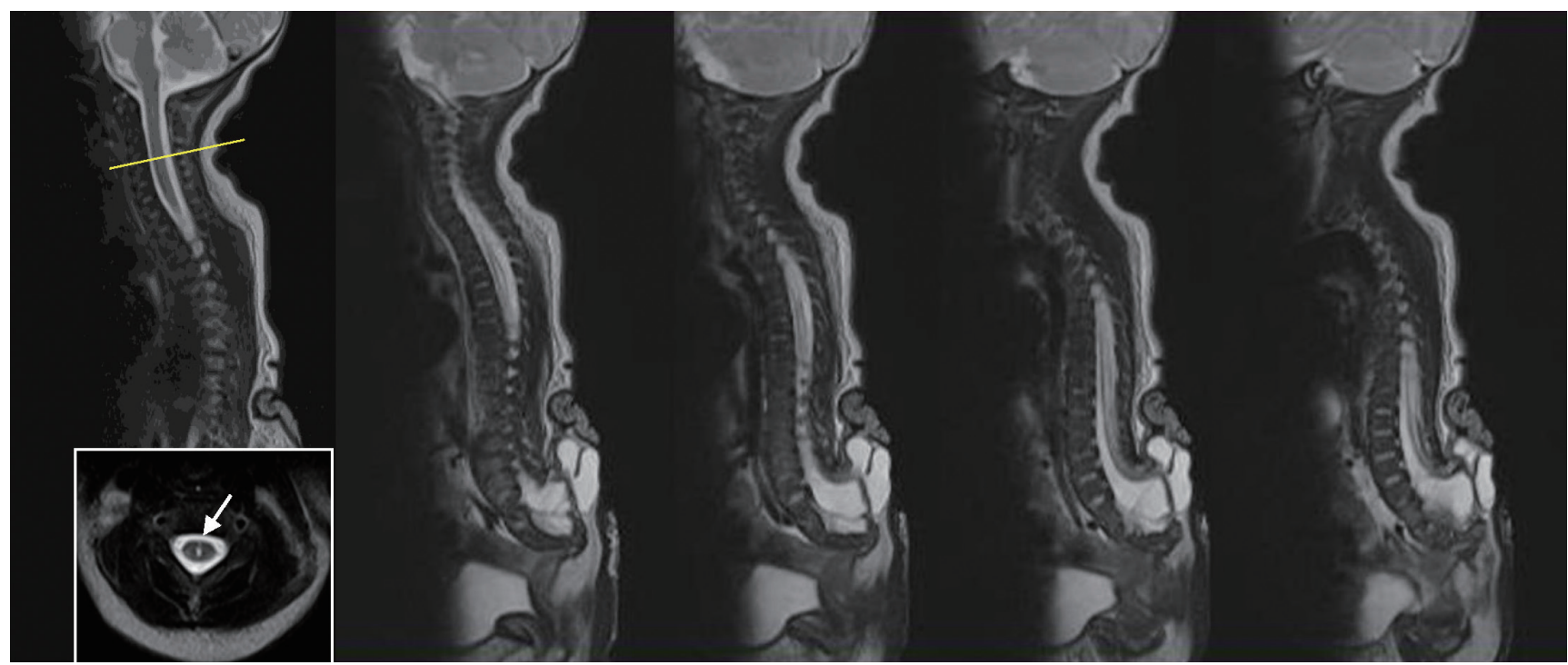

Fig. 1. Serial sagittal MRI images of a terminal myelocystocele patient showing the syringomyelia extending up to the cervical level. Inlet on the far left image shows the axial plane of the yellow line with syringomyelia (white arrow). MRI : magnetic resonance imaging.

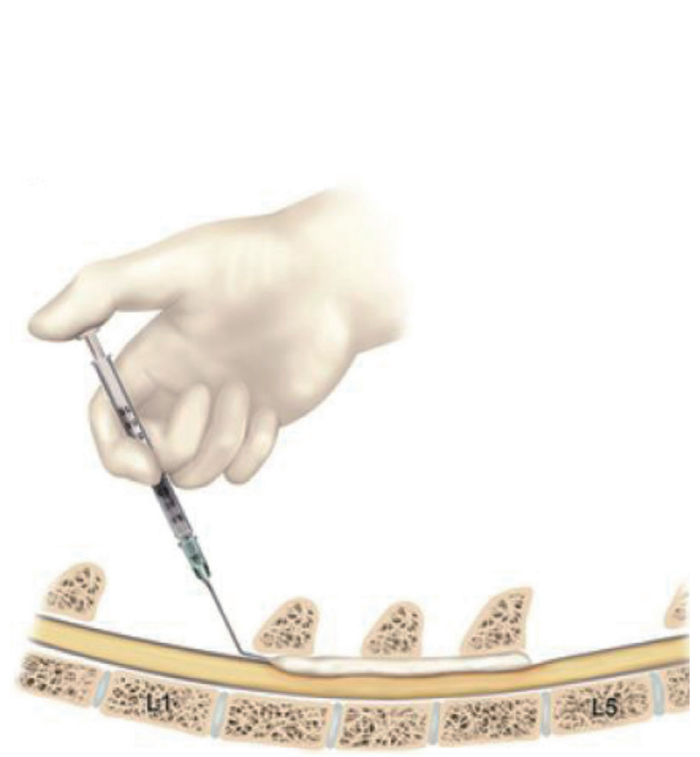

(A)
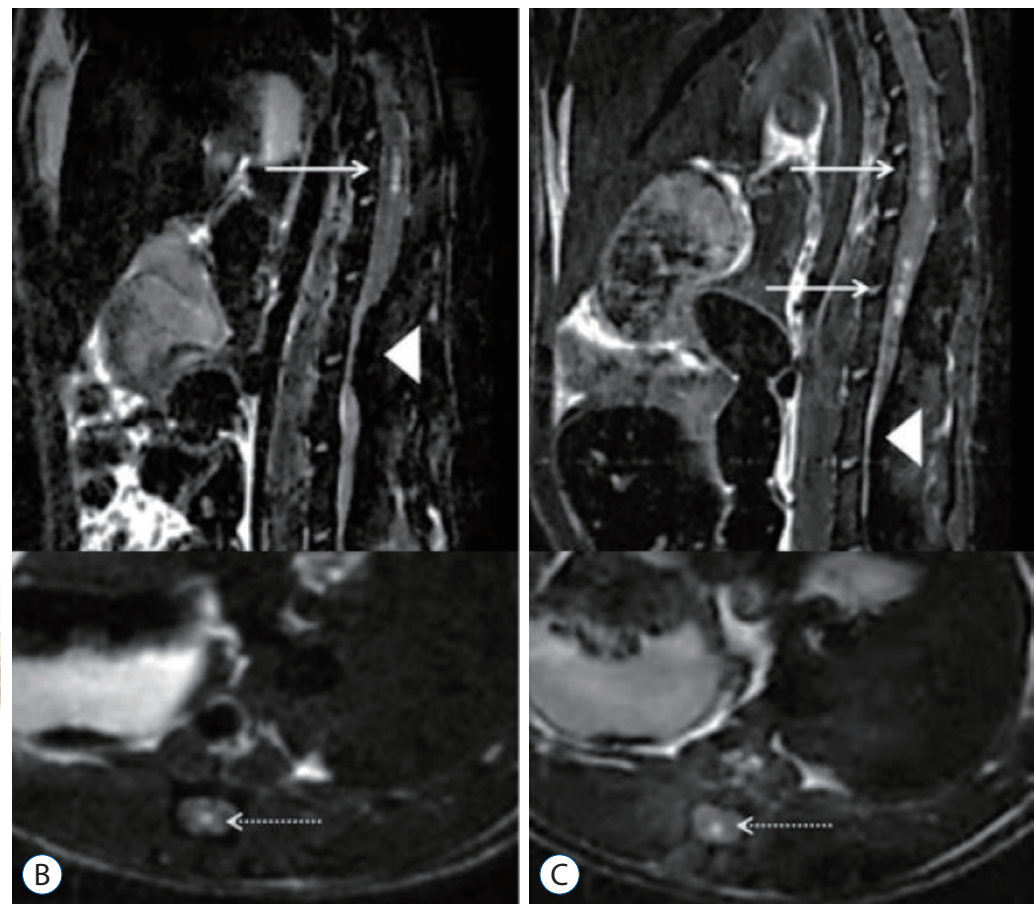

Fig. 2. A : Medical illustration of the surgical procedure of animal model of syringomyelia by epidural compression of kaolin. B : Syringomyelia in a rat : MRI obtained 3 months after injection of kaolin. C: Another example of syringomyelia shown at 3 months after the operation on sagittal (upper, arrows) and axial (lower, dotted arrow) T2-weighted images. The syrinx cavity is located cephalad to the compression site (arrowhead). Reprinted from Lee et al. ${ }^{11)}$ with permission of American Association of Neurological Surgeons. MRI : magnetic resonance imaging.

draw in interstitial fluid, causing enlargement of the syrinx ${ }^{6}$.

Another study established a rat model of syringomyelia using kaolin material to produce epidural compression ${ }^{11}$. Similar to the syrinx related to spinal dysraphism with cord tether- ing and compression, these animals developed a syrinx cephalad to the compression (Fig. 2). 


\section{DIAGNOSIS}

As it is difficult to differentiate between the symptoms caused by tethering and syringomyelia, a syrinx is most frequently detected by radiological imaging performed at the time of initial diagnosis or during the follow-up of spinal dysraphism. Magnetic resonance imaging (MRI) is the gold standard for the diagnosis of syringomyelia, and ultrasonography is also useful, especially for the follow-up of known syringomyelia cases. A recent study suggested the inefficiency of performing a whole spine MRI scan (covering the thoracic and cervical regions with both sagittal and axial scans) for patients with spinal dysraphism in the lumbosacral area ${ }^{10)}$. Then, a comment followed, mentioning the usefulness of 'extended' lumbosacral MRI (covering the thoracic and cervical regions only with sagittal scans, omitting axial scanning because it takes time due to the larger number of cuts) studies in evaluating the entire extent of the associated syringomyelia when present ${ }^{9)}$. Considering the rather frequent, significant incidence of syringomyelia in more than $20 \%$ of patients, the addition of another MRI examination with or without sedation to determine the upper extent and severity of the syrinx in such patients may be more inefficient.

\section{CLINICAL IMPLICATION}

Syringomyelia is one of the most important radiological features of cord tethering. Clinicians should be concerned about syringomyelia found at initial diagnosis, and more frequent follow-ups with intermittent imaging should be performed. If an increase in the size of the syrinx is found, surgery should be recommended promptly, as cord tethering may be progressing ${ }^{1,2,4,5)}$.

However, the mere presence of syrinx in an asymptomatic patient may not be a reason for immediate surgical intervention, especially when syrinx is not extensive ${ }^{8}$. Surgeons should not be rushed into performing untethering. Close follow-up of the syrinx and symptoms should be performed before deciding upon surgical intervention.

The status of the syrinx is also an important radiological feature during the postoperative follow-up of patients. A clear improvement of the syrinx may be a good sign that untethering was achieved. However, a 'static' syrinx after untethering does not mean that the surgery was unsuccessful, as reports show that symptomatic improvement is frequently seen in patients in whom the syrinx was unchanged after successful untethering ${ }^{8,13)}$. We have published the results of the syrinx in 33 patients, of whom 18 patients (55\%) exhibited a syrinx that decreased in size or disappeared, and nine (27\%) showed a syrinx with an unchanged size ${ }^{12}$. All of the patients either had stable or improved symptoms postoperatively. Aggravation of the syrinx is usually an important clinical indicator of retethering. The abovementioned report showed a case of retethering in which the appearance of syrinx preceded actual symptomatic deterioration, emphasizing the role of the syringomyelia as a sign of cord tethering. However, four patients showed a 'transient' increase in the size of the syrinx during the initial postoperative year. The patients were symptomatically not different from the other patients with static or improved syrinx, and the follow-up images showed a later decrease in the syrinx size. Although these results still need to be interpreted with caution, such a 'transient' increase during the first year after the operation should not be readily taken as an indication of retethering. Therefore, in the case of an enlarging syringomyelia after the operation, if it occurs after the first postoperative year, it should be considered a warning sign, whereas if it is detected during the first year, the clinicians should be aware of the possibility of a transient increase and closely observe the patient, not rushing the decision of treatment strategy.

An exceptional situation that should be kept in mind for worsening syringomyelia postoperatively is when the patient has existing ventricular shunts due to hydrocephalus. Shunt malfunction may cause an increase in the size of the syrinx.

\section{TREATMENT STRATEGY}

There has been controversy regarding whether direct manipulation of the syrinx is needed ${ }^{3,7}$. Recently, it seems that the strategy to only perform untethering has dominated. This dominance stems from the observation that resolution or improvement of the syrinx is seen after successful untethering procedures. Additionally, and more importantly, symptomatic improvement is also observed with only untethering. 


\section{CONCLUSION}

Syringomyelia associated with spinal dysraphism has important clinical implications, as syringomyelia usually implies progressive tethering. It should be taken seriously, especially during the postoperative follow-up, as it may be one of the earliest signs of retethering. However, surgeons should not rush to operate on asymptomatic patients with a small syrinx. Additionally, a static or transiently increasing syrinx after untethering usually does not imply failed surgery or retethering.

\section{CONFLICTS OF INTEREST}

No potential conflict of interest relevant to this article was reported.

\section{INFORMED CONSENT}

This type of study does not require informed consent.

\section{AUTHOR CONTRIBUTIONS}

\author{
Conceptualization : KCW, JYL \\ Data curation : KKH, JYL \\ Formal analysis : JYL \\ Methodology : KKH, JYL \\ Visualization : $\mathrm{KKH}$ \\ Writing - original draft : JYL, KCW \\ Writing - review \& editing : KKH, KCW, JYL
}

\section{ORCID}

Ji Yeoun Lee https://orcid.org/0000-0003-0464-7605 Kyung Hyun Kim https://orcid.org/0000-0002-8238-2043

Kyu-Chang Wang https://orcid.org/0000-0001-7440-6650

\section{- Acknowledgements}

This work was supported by the National Research Foundation of Korea (NRF) Grant funded by the Korean Government (MSIP) (NRF-2018R1A5A2025964).

\section{References}

1. Beaumont A, Muszynski CA, Kaufman BA : Clinical significance of terminal syringomyelia in association with pediatric tethered cord syndrome. Pediatr Neurosurg 43 : 216-221, 2007

2. Bowman RM, McLone DG, Grant JA, Tomita T, Ito JA : Spina bifida outcome: a 25-year prospective. Pediatr Neurosurg 34 : 114-120, 2001

3. Bruzek AK, Starr J, Garton HJL, Muraszko KM, Maher CO, Strahle JM : Syringomyelia in children with closed spinal dysraphism: long-term outcomes after surgical intervention. J Neurosurg Pediatr 25 : 209-300, 2020

4. Caldarelli M, Di Rocco C, La Marca F : Treatment of hydromyelia in spina bifida. Surg Neurol 50 : 411-420, 1998

5. Erkan K, Unal F, Kiris T, Karalar T : Treatment of terminal syringomyelia in association with tethered cord syndrome: clinical outcomes with and without syrinx drainage. Neurosurg Focus 8 : E9, 2000

6. Greitz D: Unraveling the riddle of syringomyelia. Neurosurg Rev 29 : 251-263; discussion 264, 2006

7. Iskandar BJ, Oakes WJ, McLaughlin C, Osumi AK, Tien RD : Terminal syringohydromyelia and occult spinal dysraphism. J Neurosurg 81 : 513-519, 1994

8. Kashlan ON, Wilkinson DA, Morgenstern H, Khalsa SS, Maher CO : Predictors of surgical treatment in children with tethered fibrofatty filum terminale. J Neurosurg Pediatr 25 : 97-208, 2020

9. Kim KH, Lee JY, Cheon JE, Kim IO, Wang KC : A suggestion to the article "Whole spine MRI is not required in investigating uncomplicated paediatric lumbosacral lipoma: a retrospective single-institution review": extended lumbosacral spine MRI. Childs Nerv Syst 36 : 7-8, 2020

10. Layard Horsfall $H$, Chari A, Huttunen T, Simcock C, D'Arco F, Thompson $D$ : Whole spine MRI is not required in investigating uncomplicated paediatric lumbosacral lipoma. A retrospective single-institution review. Childs Nerv Syst 35 : 2163-2169, 2019

11. Lee JY, Kim SW, Kim SP, Kim H, Cheon JE, Kim SK, et al. : A rat model of chronic syringomyelia induced by epidural compression of the lumbar spinal cord. J Neurosurg Spine 27 : 458-467, 2017

12. Lee JY, Phi JH, Cheon JE, Kim SK, Kim IO, Cho BK, et al. : Preuntethering and postuntethering courses of syringomyelia associated with tethered spinal cord. Neurosurgery $71:$ 23-29, 2012

13. Tsitouras V, Sgouros $S$ : Syringomyelia and tethered cord in children. Childs Nerv Syst 29 : 1625-1634, 2013 